\title{
Evaluation of tri-junction solar cells response to electrons and protons of the JUICE specific environment
}

\author{
Sophie Duzellier ${ }^{1}$, Thierry Nuns ${ }^{1}$, Jean Pierre David ${ }^{1}$, Claude Pons $^{1}$, Romain Rey ${ }^{1}$, Cyril Cavel ${ }^{2}$, Guilhem \\ Chanteperdrix $^{2}$ \\ ${ }^{1}$ ONERA, 2 avenue Belin, Toulouse, 31055, France \\ ${ }^{2}$ Airbus DS, 31 rue des cosmonautes, Toulouse, 31400, France
}

\begin{abstract}
Degradation of 3G28C Tri-Junction Solar cells from AZUR SPACE has been evaluated for the specific JUICE radiation environment. Data from $1 \mathrm{MeV}$ electrons, protons and combined irradiations with in situ measurements is presented on different sets of full scale 3J cells. Analysis is focused on the influence of low temperature, the presence of annealing, and equivalence of damage dose degradation.
\end{abstract}

Index Terms - tri-junction solar cells, electrons, protons, damage dose degradation.

\section{INTRODUCTION}

Space radiations are of concern because strongly affect the long-term performance of most active semi-conductor devices on-board spacecraft. Solar Generator Subsystem (SGS) are particularly exposed to solar and trapped particles as not shielded by spacecraft structure. High levels of doses are therefore expected through Solar Cells.

JUpiter ICy moons Explorer (JUICE) is the first L-class mission in ESA's Cosmic Vision Program to be launched in 2022. The objective of this mission is the investigation of Jupiter and its icy moons. The mission scenario features an interplanetary transfer of about 7.5 years, the "Jovian tour" itself including several flybys of Callisto, Europa and Ganymede. The mission ends with an orbital phase around Ganymede where the radiation dose will constantly increase at a fast rate.

These phases are critical in terms of radiation. The Solar Cell Assembly (SCA) is first degraded during the cruise under the influence of solar protons. Then a harsh radiation environment (electrons and protons) is trapped by the Jupiter magnetosphere. The expected cumulated dose corresponds to $1 \mathrm{MeV}$ electron-equivalent fluence of $2.5-310^{15} \mathrm{e}-/ \mathrm{cm}^{2}$ (EndOf-Life-EOL- fluence).

Additionally, very specific thermal conditions are encountered: at Jupiter where the operating temperature will be around $-120^{\circ} \mathrm{C}$ with very low (photons) solar flux (between $46 \mathrm{~W} / \mathrm{m}^{2}$ and $54 \mathrm{~W} / \mathrm{m}^{2}$ at Jupiter i.e. 5.2AU), and coldest temperature at eclipse exit as low as $-220^{\circ} \mathrm{C}$.

The JUICE Solar Generator Subsystem (SGS) baseline design consists in two identical deployable wings. The baseline Photovoltaic Assembly (PVA) design is based on $40 \mathrm{~mm} \times 80 \mathrm{~mm}$ tri-junctions (3J) solar cells of type $3 \mathrm{G} 28 \mathrm{C}$ from AZUR Space with a thickness of $80 \mu \mathrm{m}$, an external bypass diode and a $300 \mu \mathrm{m}$ ITO coated and grounded cover glass. Each panel of the SGS constitutes one section, made of 124 strings of 18 cells in series. The SGS therefore contains 23500 solar cells (10 panels). The EOL power requirement applicable is $730 \mathrm{~W}$.

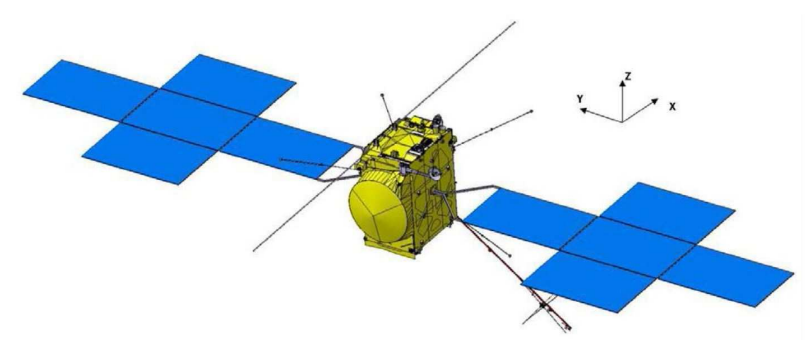

Fig. 1. JUICE spacecraft and solar generator subsystem

SGS design relies on "accurate" estimate of radiation constraints but also representative ground testing of solar cells from flight lot. For the particular case of JUICE mission, ideally low (irradiation and test) temperature conditions and very low solar flux level shall be applied at ground testing. However to avoid time consuming and costly test campaigns, the possibility to perform room temperature (RT) testing was investigated through extensive testing conducted on $2 \times 2 \mathrm{~cm}^{2}$ bare cells in the course of technological development activities [1]-[4].

It was shown that solar cells irradiated and measured at low temperature exhibit a strong recovery effect within short time (10 minutes) after the irradiation but also after short RT phase with the absolute value of the observed recovery depending on the fluence and particle species.

It was also demonstrated that the degradation of the maximum power, Pmp, is much stronger than the degradation of Isc and Voc values. It was thus concluded that a correct determination of the EOL solar cell performance at LILT conditions shall be based on the extraction of corresponding annealing coefficients from in-situ measurements.

These observations could not be made on optimized LILT full scale cells $\left(4 \times 8 \mathrm{~cm}^{2}\right)$ because requiring ex situ transfer to test capabilities and thus received RT annealing between end of irradiation and measurements.

This paper reports on new extensive test campaign performed on full scale $3 \mathrm{G} 28 \mathrm{C}$ bare solar cells to determine 
EOL performance for the JUICE mission. This investigation is carried out with electrons, protons or combined electron/proton irradiations, at low temperature and for the first time with in situ testing. Analysis of data explores the temperature dependence of degradation, the potential annealing mechanisms, the influence of cell size (large versus small coupons) and the benefit to perform combined irradiation to simulate full dose profile.

\section{TEST PLAN AND FACILITIES}

The test plan includes the irradiation and testing at low temperature of full scale $\left(4 \times 8 \mathrm{~cm}^{2}\right.$ with cropped corners) bare 3G28 cells:

1) At different fluences (nominal and double) with $1 \mathrm{MeV}$ electrons (e-) and protons $(\mathrm{p}+)$ separately,

2) With combined $1 \mathrm{MeV}$ protons and electrons irradiation.

Tables I and II summarize test conditions and generic sequence (similar as the one uses in [1] and [2] but with updated JUICE thermal requirement).

TABLE I

TEST CONDITIONS

\begin{tabular}{|c|c|c|c|c|c|}
\hline Test ID & Batch & Count & Particle & $\begin{array}{l}\text { Fluence } \\
\# / \mathrm{cm}^{2}\end{array}$ & $\begin{array}{l}\text { Flux } \\
\# / \text { s.cm² }\end{array}$ \\
\hline Nominal e- & 1725 & 10 & \multirow[b]{2}{*}{ Electron } & $1.510^{15}$ & $1.810^{11}$ \\
\hline Double e- & $\begin{array}{l}1725- \\
1726\end{array}$ & 10 & & $310^{15}$ & $1.810^{11}$ \\
\hline Nominal p+ & \multirow{2}{*}{1725} & 14 & \multirow{2}{*}{ Proton } & $210^{11}$ & $1-310^{8}$ \\
\hline Double $\mathrm{p}+$ & & 10 & & $410^{11}$ & $1-310^{8}$ \\
\hline \multirow{2}{*}{ Combined } & \multirow{2}{*}{1725} & \multirow[b]{2}{*}{18} & Proton & $210^{11}$ & $1-310^{8}$ \\
\hline & & & Electron & $7.210^{14}$ & $510^{10}$ \\
\hline
\end{tabular}

TABLE II

GENERIC TEST SEQUENCE

\begin{tabular}{|l|l|l|}
\hline Step ID & Step\# & Description \\
\hline RT air & Step0 & initial air RT \\
\hline RT vacuum & Step1 & initial vacuum RT \\
\hline$-100^{\circ} \mathrm{C}$ & Step2 & $-100^{\circ} \mathrm{C}$ \\
\hline$-125^{\circ} \mathrm{C}$ & Step3 & $-125^{\circ} \mathrm{C}$ \\
\hline$-125^{\circ} \mathrm{C}$ & Step4 & Irradiation (e-, p+ or combined) \\
\hline$-125^{\circ} \mathrm{C}$ IR1 & Step5 & $\begin{array}{l}-125^{\circ} \mathrm{C} \text { post irradiation } \\
(\text { end of step } 4+7-10 \text { min })\end{array}$ \\
\hline$-125^{\circ} \mathrm{C}$ IR2 & Step6 & $-125^{\circ} \mathrm{C}$ post irradiation step5 $\left.+15 \mathrm{~min}\right)$ \\
\hline$-125^{\circ} \mathrm{C}$ IR3 & Step7 & $-125^{\circ} \mathrm{C}$ post irradiation (step $\left.6+15 \mathrm{~min}\right)$ \\
\hline$-100^{\circ} \mathrm{C}$ IR1 & Step8 & $-100^{\circ} \mathrm{C}$ post irradiation \\
\hline RT IR1 & Step9 & RT post irradiation \\
\hline$-100^{\circ} \mathrm{C}$ IR2 & Step10 & $-100^{\circ} \mathrm{C}$ post irradiation after RT \\
\hline$-125^{\circ} \mathrm{C}$ IR4 & Step11 & $-125^{\circ} \mathrm{C}$ post irradiation after RT \\
\hline$-100^{\circ} \mathrm{C}$ IR3 & Step12 & $-100^{\circ} \mathrm{C}$ post irradiation before final RT \\
\hline RT fin & Step13 & final vacuum RT \\
\hline
\end{tabular}

Nominal and double testing configurations provide min/max predicted degradation for separate electron and proton contribution, whereas combined testing reproduces expected electron and proton displacement damage dose for mission (mission equivalent fluence).
Contrary to nominal fluence tests, "double" and combined tested samples belong to 2 different batches.

The irradiation and testing temperature is set to the expected operating one (steps 3 to 7). Steps 5-7 aim at investigating annealing at low temperature, step 11 annealing after warming up to room temperature (RT). Irradiation step 4 is two-fold for combined configuration: first electron then proton exposure with intermediate low temperature testing $(\approx 1-2 \mathrm{~h}$ between exposure including proton beam setting and adjustment).

The experiments have been carried out at ONERA DPHY department in Toulouse with existing facilities (Fig. 2). The MIRAGE chamber (AXEL lab.) allows for electron and proton irradiations, sun solar spectrum exposure through glass window, thermal regulation of sample plate and electrical feedthrough for in situ testing. Two full scale cells are irradiated at once but tested one-by-one (Fig. 3).

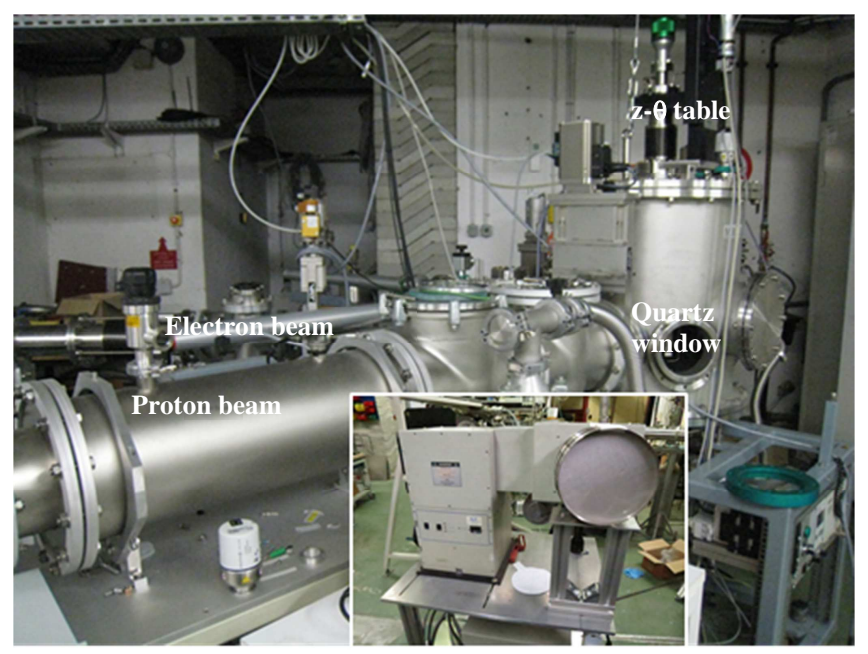

Fig. 2. MIRAGE chamber and Xe Oriel sun simulator at ONERADPHY Toulouse [5].

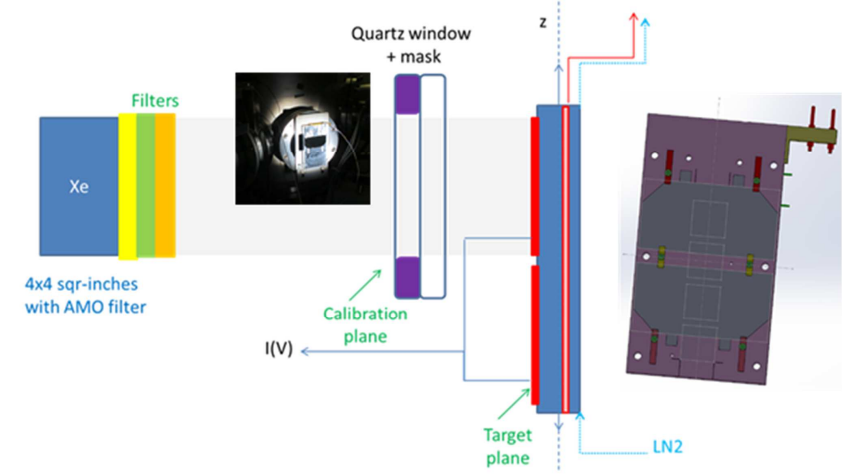

Fig. 3. Solar cell test bench and cooled sample plate. Calibration is performed in target plane prior each test campaign the ex situ for checking at each step of measure.

The Solar cell test bench allows for I-V measurement in dark/illumination conditions (Dark I(V) or DIV, Light I(V) or LIV). At each step, DIV is performed first the LIV and each measurement is done twice. 
The illumination setup is composed of a $1000 \mathrm{~W}$ sun simulator (Xenon lamp, class ABA IEC2007) fitted with AM0 filter. The 3.7\% AM0 illumination level is applied to each cell for Light I(V) acquisition at each step of Table II. Nonuniformity was measured to be $\approx 3-5 \%$ across a single cell. Before each test campaign, calibration is performed in target plane with reference cells and spectro-radiometer in the 200$800 \mathrm{~nm}$ range. The reference (top) cell is then used at each measurement step for checking and adjusting level of illumination in the calibration plane (before the quartz window).

To obtain a good estimate of average parameters and spread over the 10 samples statistics per test configuration, special care was taken to optimize critical experimental parameters such as

- Temperature accuracy $\left( \pm 0.6^{\circ} \mathrm{C}\right)$ and stability under irradiation (especially with electron due to beaminduced heating) and measure,

- Particle energy accuracy is better than $1 \%$,

- Fluence is monitored in real time with faraday cups in target plane. Beam spot area is $14 \times 14 \mathrm{~cm}^{2}$ therefore 2 larges cells can be irradiated concurrently with nonuniformity $\approx 10 \%$ for electron (scattered beam) but in the $15-25 \%$ range for proton (swept beam with very low current -few tens of $\mathrm{pA} / \mathrm{cm}^{2}$ - out of standard conditions for Van de Graaff machines),

- Measured LIV reproducibility is 2\% (linked to variability of illumination level as set by $\mathrm{I}_{\mathrm{SC}}$ current of reference top cell)

\section{MAIN RESULTS}

As previously mentioned, main parameters monitored during these test campaigns were $\mathrm{I}_{\mathrm{sc}}, \mathrm{V}_{\mathrm{oc}}, \mathrm{P}_{\max }$ and $\mathrm{FF}$ and special attention was put on 1) degradation level, 2) annealing at low temperature and 3) after warming up at RT.

\section{A. Degradation and annealing at $-125^{\circ} \mathrm{C}$}

Typical response is provided in Fig. 4 and Fig. 5 showing resp. $I_{s c}$ and $V_{o c}$ parameters at each step of the "nominal e-" testing and LIV main curves for "double e-" test sequence.

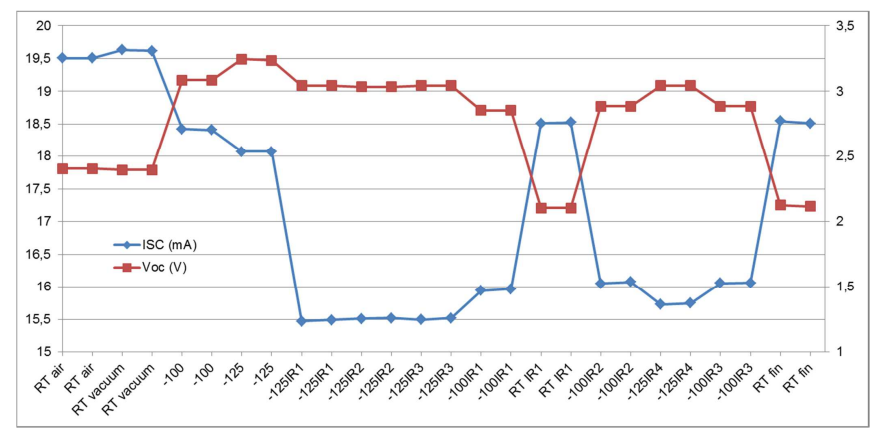

Fig. 4. $\mathrm{I}_{\mathrm{sc}}$ and $\mathrm{V}_{\mathrm{oc}}$ parameters at each step of "nominal e-" testing.

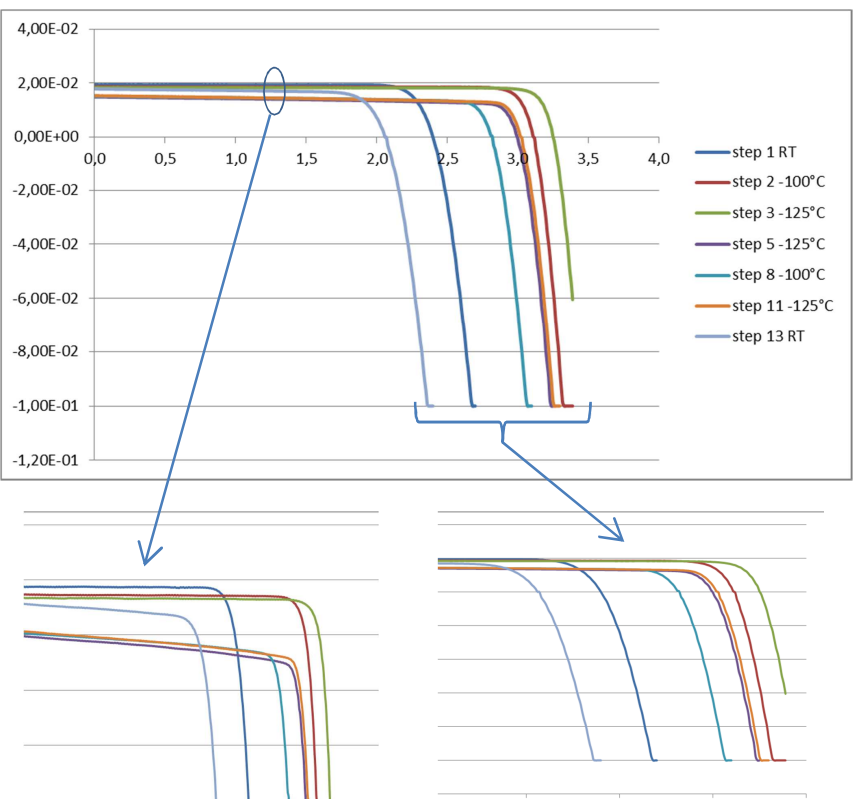

Fig. 5. (top) LIV curves (current vs voltage) for main steps of the test sequence, (bottom) zoom on y and $\mathrm{x}$ scales.

First observation is that, whatever the test conditions, no annealing is observed at low temperature from 10 minutes after the end of the irradiation as reported in [1] (steps 5-7 i.e. -125 IR $1-3,<<1 \%$ as disclosed in Table III). This conclusion was also drawn from electron test campaigns performed with $2 \times 2 \mathrm{~cm}^{2}$ bare cells at the same set up at ONERA prior to the full scale cell testing (same electron test sequence and timing). However, one cannot confirm the presence of annealing over a shorter timescale as reported in [1] due to delay before first LIV acquisition (access to the irradiation room, checking of illumination and DIV measured first). And yet, no estimate of this (unavoidable) delay is provided in [1] to allow for concluding on this point.

TABLE III

MEAN ANNEALING AT $-125^{\circ} \mathrm{C}$ IN \% FOR ALL CONFIGURATIONS

\begin{tabular}{|l|c|l|l|l|l|}
\hline & nom. e- & double e- & nom. $\mathrm{p}+$ & double $\mathrm{p}+$ & combined \\
\hline $\mathrm{I}_{\mathrm{sc}}$ & $0,16 \%$ & $0,21 \%$ & $0,13 \%$ & $0,19 \%$ & $0,14 \%$ \\
\hline $\mathrm{V}_{\mathrm{oc}}$ & $0,15 \%$ & $0,17 \%$ & $0,19 \%$ & $0,33 \%$ & $0,23 \%$ \\
\hline $\mathrm{P}_{\max }$ & $0,28 \%$ & $0,27 \%$ & $0,28 \%$ & $0,33 \%$ & $0,28 \%$ \\
\hline $\mathrm{FF}$ & $0,13 \%$ & $0,30 \%$ & $0,19 \%$ & $0,21 \%$ & $0,23 \%$ \\
\hline
\end{tabular}

On Fig.5, one can clearly see the effect of temperature (voltage increase, bottom right) and irradiation (especially bottom left). Slight shift between step 5 and step 11 curves is representative of annealing due to heating up to RT (step 9).

Contrary to what is reported in [1] and [2] on $2 \times 2 \mathrm{~cm}^{2}$ coupons, the drop of the current in the LIV characteristics is here linear and starts from $0 \mathrm{~V}$. It can be correlated to the dark current increase as disclosed in Fig. 6. 


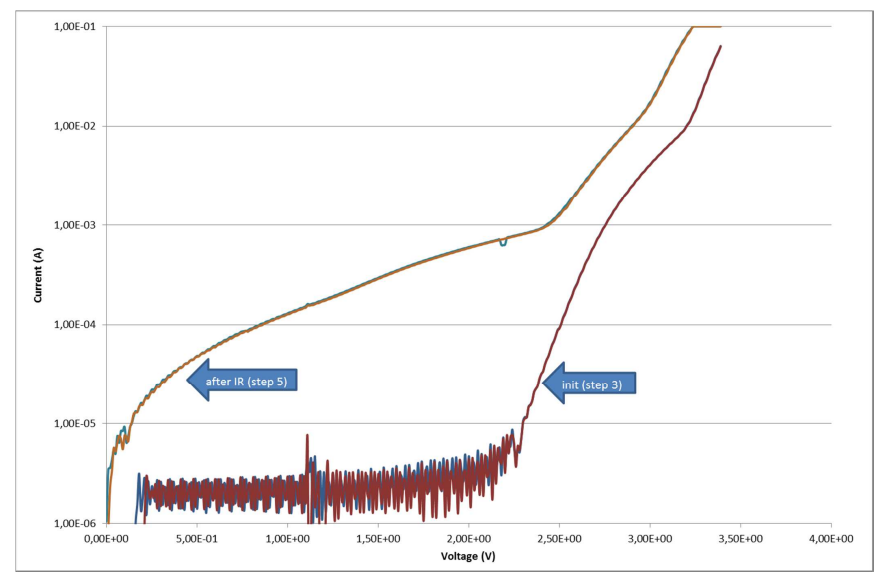

Fig. 6. DIV curves (current vs voltage) for steps 3 and 5 of the "double e-" test sequence.

In [2] the change in the LIV curve is assumed to be the consequence of a radiation-induced tunneling current taking place in the top and bottom sub-cells leading to $\mathrm{P}_{\max }$ degradation level much greater than $\mathrm{I}_{\mathrm{sc}}$ and $\mathrm{V}_{\mathrm{oc}}$ ones.

We do observe here again this significant higher $\mathrm{P}_{\max }$ degradation as disclosed in Table IV.

TABLE IV

MEAN DEGRADATION AT $-125^{\circ} \mathrm{C}$ FOR ALL CONFIGURATIONS

\begin{tabular}{|l|l|l|l|l|l|}
\hline & Nnm. e- & double e- & nom. p+ & double p+ & combined \\
\hline $\mathrm{I}_{\mathrm{sc}}$ & $-12,3 \%$ & $-17,9 \%$ & $-6,1 \%$ & $-10,7 \%$ & $-12,0 \%$ \\
\hline $\mathrm{V}_{\mathrm{oc}}$ & $-6,5 \%$ & $-7,7 \%$ & $-7,8 \%$ & $-8,9 \%$ & $-8,8 \%$ \\
\hline $\mathrm{P}_{\max }$ & $-21,9 \%$ & $-34,8 \%$ & $-18,2 \%$ & $-24,3 \%$ & $-27,2 \%$ \\
\hline $\mathrm{FF}$ & $-4,8 \%$ & $-13,9 \%$ & $-5,6 \%$ & $-7,0 \%$ & $-9,3 \%$ \\
\hline
\end{tabular}

\section{Annealing at room temperature}

The validity of a RT test approach for JUICE solar cell also relies on potential annealing mechanisms taking place at RT and accurate estimate of the associated annealing coefficient. And indeed, recovery could be measured after warming up (delta between step 11 and steps 5-7) with $\mathrm{P}_{\max }$ and FF parameters recovery level being fluence-dependent: the higher the fluence the higher the annealing (Fig.7 with protons).

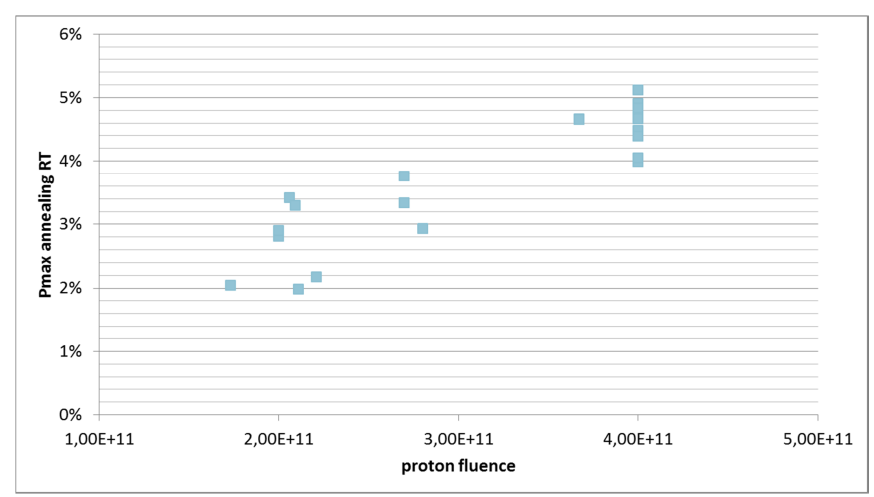

Fig. 7. RT annealing of $\mathrm{P}_{\max }$ in \% versus proton fluence.
It is also shown in Table $\mathrm{V}$ with "double/nominal configurations" ratios either for electron and proton testing of 1.6-1.8 for $\mathrm{P}_{\max }, 2$ for FF whereas "combined" recovery is of the order of the sum of "nominal testing" outputs (even if nominal electron fluence is twice the combined electron fluence).

\section{TABLE V}

MEAN ANNEALING AT RT IN \% FOR ALL CONFIGURATIONS

\begin{tabular}{|l|c|c|c|l|l|}
\hline & nom. e- & double e- & nom. $\mathrm{p}+$ & double $\mathrm{p}+$ & combined \\
\hline $\mathrm{I}_{\mathrm{sc}}$ & $1,22 \%$ & $0,93 \%$ & $0,77 \%$ & $1,67 \%$ & $1,88 \%$ \\
\hline $\mathrm{V}_{\mathrm{oc}}$ & $0,59 \%$ & $0,49 \%$ & $1,02 \%$ & $1,20 \%$ & $1,39 \%$ \\
\hline $\mathrm{P}_{\max }$ & $2,91 \%$ & $4,63 \%$ & $2,57 \%$ & $4,53 \%$ & $5,51 \%$ \\
\hline $\mathrm{FF}$ & $1,15 \%$ & $3,16 \%$ & $0,76 \%$ & $1,59 \%$ & $2,14 \%$ \\
\hline
\end{tabular}

Recovery amplitude is $\leq 3 \%$ here at small fluence, quite similar with what is reported in [1] and within the measure uncertainty accounting for all variability parameters (illumination, flux and ffuence, part-to-part variation...), it is larger at larger fluence ("double fluence" testing and combined conditions) however limited to $5.5 \%$ at the most for $\mathrm{P}_{\max }$ in the "combined" testing configuration (compared to $12 \%$ in [1] in case of electron irradiation) whereas again $\leq 3 \%$ for other parameters.

\section{FURTHER ANALYSIS}

\section{A. Data spreading}

BOL and EOL parameters are disclosed in Table VI (BOL step 1- and EOL data-step 13- both at room temperature).

TABLE VI

MEAN BOL \& EOL PARAMETERS \& STD-DEVIATION $\sigma$

\begin{tabular}{|c|c|c|c|c|c|c|c|c|}
\hline & \multicolumn{2}{|l|}{$I_{s c}$} & \multicolumn{2}{|l|}{$\overline{V_{o c}}$} & \multicolumn{2}{|l|}{$\mathrm{P}_{\max }$} & \multicolumn{2}{|l|}{$\mathrm{FF}$} \\
\hline & Bol & Eol & Bol & Eol & Bol & Eol & Bol & Eol \\
\hline \multicolumn{9}{|c|}{ Nominal electrons } \\
\hline Avg & 19,6 & 18,9 & 2,39 & 2,12 & 39,5 & 32,5 & 0,84 & 0,81 \\
\hline$\sigma$ & 0,12 & 0,23 & 0,02 & 0,01 & 0,90 & 0,49 & 0,01 & 0,004 \\
\hline \multicolumn{9}{|c|}{ Double electrons } \\
\hline Avg & 19,5 & 17,8 & 2,40 & 2,07 & 39,6 & 28,7 & 0,85 & 0,78 \\
\hline$\sigma$ & 0,17 & 0,19 & 0,01 & 0,01 & 0,67 & 0,54 & 0,01 & 0,02 \\
\hline \multicolumn{9}{|c|}{ Nominal protons } \\
\hline Avg & 19,6 & 19,4 & 2,41 & 2,01 & 40,3 & 30,6 & 0,85 & 0,79 \\
\hline$\sigma$ & 0,10 & 0,08 & 0,01 & 0,03 & 0,30 & 0,69 & 0,004 & 0,01 \\
\hline \multicolumn{9}{|c|}{ Double protons } \\
\hline Avg & 19,5 & 19,5 & 2,42 & 2,03 & 40,5 & 31,4 & 0,86 & 0,79 \\
\hline$\sigma$ & 0,15 & 0,19 & 0,01 & 0,05 & 0,47 & 1,38 & 0,004 & 0,01 \\
\hline \multicolumn{9}{|c|}{ Combined } \\
\hline$\overline{\mathrm{Avg}}$ & 19,5 & 19,5 & 2,42 & 2,03 & 40,5 & 31,4 & 0,86 & 0,79 \\
\hline$\sigma$ & 0,15 & 0,19 & 0,01 & 0,05 & 0,47 & 1,38 & 0,004 & 0,01 \\
\hline
\end{tabular}

There is no general rule regarding dependence of EOL data spreading with fluence or species: BOL data spreading is 
generally very limited, slightly greater for "double fluence" configurations probably due to batch-to-batch variation.

EOL data spreading is of same order of magnitude than BOL data in case of electrons. However, EOL proton $\mathrm{P}_{\max }$ dispersion confirms to be much larger (x2-3), as for combined data spread. The impact of fluence is not clear.

\section{B. degradation versus fluence and displacement damage dose}

Degradation at low temperature was measured for several proton and electron fluence: in the $1.810^{11}$ to $410^{11} \mathrm{p}+/ \mathrm{cm}^{2}$ range for protons and in the $7.210^{14}-310^{15} \mathrm{e}-/ \mathrm{cm}^{2}$ range for electrons.

Fig. 8 and Fig. 9 disclose $\mathrm{P}_{\max }$ degradation versus proton and electron fluence.

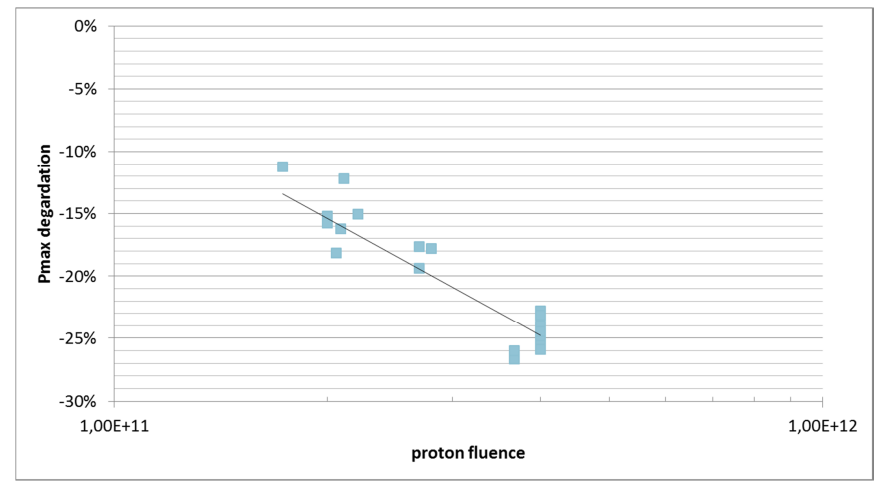

Fig. 8. Degradation of $\mathrm{P}_{\max }$ in \% versus proton fluence.

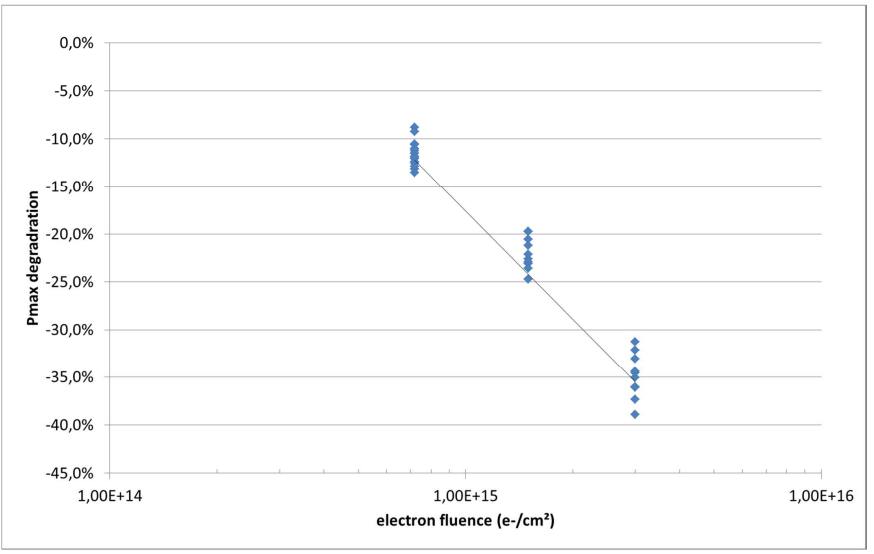

Fig. 9. Degradation of $\mathrm{P}_{\max }$ in \% versus electron fluence

From these graphs, it is clear that proton degradation is fluence-dependent following a Log-dependence law as reported in [6] and [7].

In these papers, it is also proposed the fitting of EOL/BOL parameter ratios (or Remaining Factor RF) with function expressed in terms of the NIEL dose or displacement damage dose (DDD method [8]) in middle cell (GaAs). Therefore, the comparison of combined data with separate electron and proton contributions at low temperature is provided in Fig. 10.

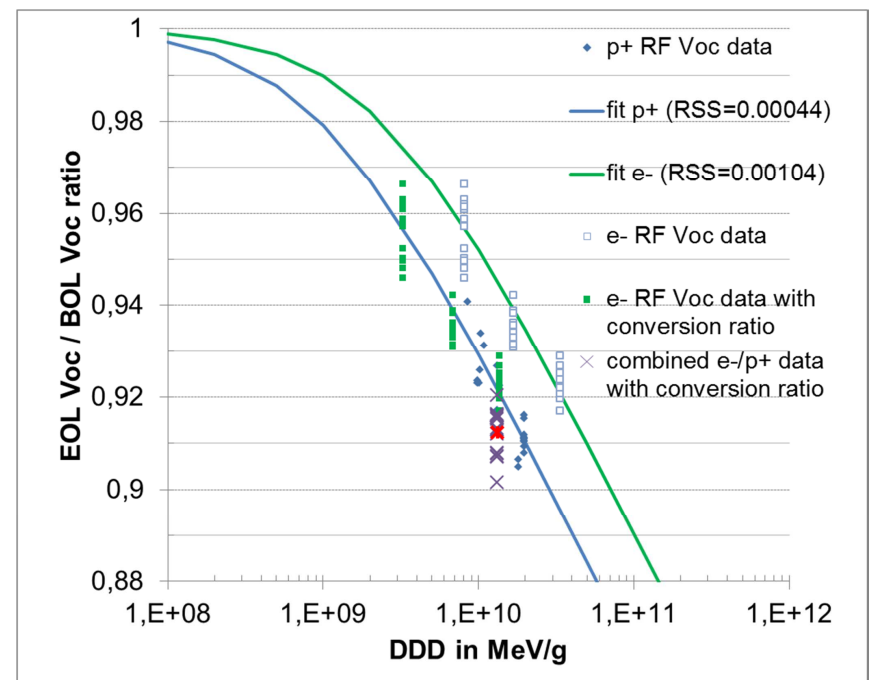

Fig. 10. $\mathrm{V}_{\mathrm{oc}}$ remaining factor $\mathrm{RF}$ at $-125^{\circ} \mathrm{C}$ versus displacement damage dose in GaAs for all tested solar cells with electrons, protons and combined electron/proton testing (red symbol is mean "combined" data).

$\mathrm{V}_{\mathrm{oc}} \mathrm{RF}$ is presented here as a function of displacement damage dose in middle cell (GaAs) with $1 \mathrm{MeV}$ electron and proton NIELs calculated for threshold energy $E_{d}=21 \mathrm{eV}$ [7] $\left(\right.$ NIEL $(\mathrm{e}-)=1.12510^{-5} \mathrm{MeV} \cdot \mathrm{cm}^{2} / \mathrm{g}, \operatorname{NIEL}(\mathrm{p}+)=0.0497$ $\mathrm{MeV} . \mathrm{cm}^{2} / \mathrm{g}$ ). The "fit" curves (blue and green) for both electron and proton data are calculated with following equation:

$$
R F=A-C \log \left(1+\frac{D D D}{D_{0}}\right)
$$

with $\mathrm{A}, \mathrm{C}$ and $\mathrm{D}_{0}$ the fitting parameters here (minimizing the residual sum of square RSS). Here $A$ is set to $1, C$ is considered identical for proton and electron fittings $\left(\mathrm{C}_{\mathrm{e}-}=\right.$ $\left.\mathrm{C}_{\mathrm{p}+}=0.0671\right)$. On the graph, the $\mathrm{D}_{0(\mathrm{p}+) /} \mathrm{D}_{0(\mathrm{e}-)}$ ratio is used to convert electron DDD into proton DDD (green square symbols and electron contribution into combined DDD). Here it was found $\mathrm{D}_{0(\mathrm{p}+)}=9,610^{8} \mathrm{MeV} / \mathrm{g}$ and $\mathrm{D}_{0(\mathrm{e}-)}=2,3810^{9}$ $\mathrm{MeV} / \mathrm{g}$.

It can be noticed in Fig.10 that all data line up with reasonable agreement showing that this approach can be used for LILT conditions.

\section{CONCLUSIONS}

A large set of tri-junction solar cells for JUICE mission have been extensively tested at low temperature under electron, proton and electron/proton combined exposure and with in situ dark and light $\mathrm{I}(\mathrm{V})$ measurements. Test configurations also allowed to measure expected degradation levels of critical parameters at different fluence on a statistically meaningful set of $3 \mathrm{~J}$ samples.

Electron, proton and combined degradations at low temperature fit quite well with the displacement damage dose approach considering the middle cell is the main contributor to the $3 \mathrm{~J}$ degradation. 
Annealing effects have been investigated and RT annealing coefficients measured with accuracy so that one can make use of these coefficients in a room-temperature test approach for the final mission qualification phase.

\section{REFERENCES}

[1] V. Khorenko, C. Baur, G. Siefer, M. Schachtner, S. Park, B. Boizot, J.C. Bourgoin, M. Casale and R. Campesato, "BOL and EOL Characterization of AZUR 3G LILT solar cells for ESA JUICE mission", Proc. of the 11th European Space Power Conference, Vol. 16, p. 120, 2017.

[2] S. Park, J.C. Bourgoin, O. Cavani, V. Khorenko, C. Baur, B. Boizot, "Origin of the degradation of triple junction solar cells at low temperature," Proc. of the 11th European Space Power Conference, Vol. 16, p. 147, 2017.

[3] V. Khorenko, G. Strobl, C. Baur, G. Siefer, J.C. Bourgoin, M. Casale, R. Campesato, S. Duzellier, and V. Inguimbert, "Performance analysis of AZUR 3G28 triple-junction solar cells optimized for operation in Jupiter environment," Proc. of 10th European Space Power Conference, pp.613-618, 2014.
[4] C. Baur, V. Khorenko, G. Siefer, J.C. Bourgoin, M. Casale, R. Campesato, S. Duzellier, and V. Inguimbert, "Development status of triple-junction solar cells optimized for low intensity low temperature applications", Proc. of the 39th IEEE Photovoltaic Specialist Conference, 2013, pp. 3237-3242.

[5] S. Duzellier, L. Artola, G. Hubert, C. Inguimbert, T. Nuns, S. Lewandowski, T. Paulmier, B. Dirassen, R. Rey, C. Pons, "AXEL lab.: representative ground simulation for investigating radiation effects in materials and electronics", presented at RADECS data workshop, 2017.

[6] C. Baur, M. Gervasi, P. Nieminen, S. Pensotti, P.G. Rancoita, M. Tacconi, "NIEL Dose dependence for solar cells irradiated with electrons and protons", Proc. of the 13th ICATPP Conference on Astroparticle, Particle, Space Physics and Detectors for Physics Applications, 2013, p.692-707.

[7] M. Salzberger, C. Nömayr, P. Lugli, S.R. Messenger, C.G. Zimmermann, "Degradation fitting of irradiated solar cells using variable threshold energy for atomic displacement", Prog. Photovolt: Res. Appl., Vol. 25, pp. 773-781, 2017.

[8] S.R. Messenger, E.M. Jackson, J.H. Warner, R.J. Walters, "SCREAM: a New code for solar cell degradation prediction using the displacement damage dose approach", in $35^{\text {th }}$ IEEE Photovoltaic Specialists Conference, 2010, pp. 1106-1111. 